Для цитирования: Борисов С. В. Энциклопедия философской практики (рецензия на книгу:

Amir L. Taking Philosophy Seriously, Cambridge Scholars Publishing, 2018, 504 pp.) // Социум и власть. 2019. № 2 (76). С. 132-137.

УДК 1(091) + $101.1+101.9$

ЭНЦИКЛОПЕДИЯ ФИЛОСОФСКОЙ ПРАКТИКИ

(РЕЦЕНЗИЯ НА КНИГУ: AMIR L. TAKING PHILOSOPHY SERIOUSLY, CAMBRIDGE SCHOLARS PUBLISHING, 2018, 504 pp.) ${ }^{1}$

Борисов Сергей Валентинович,

доктор философских наук, профессор,

Южно-Уральский государственный гуманитарно-педагогический университет, Южно-Уральский государственный университет (Национальный исследовательский университет) Российская Федерация, 454080, Челябинск, пр. Ленина, 69 E-mail: borisovsv69@mail.ru

Аннотация Статья представляет собой рецензию на книгу Лидии Амир «Принимая философию всерьез» (Cambridge Scholars Publishing, 2018). Книга синтезирует академическую и практическую философию, инициирует их диалог. Автор придерживается мелиористского взгляда на философию, который дает новое видение ее традиционных проблем, способствует новым формам ее изучения и обеспечивает признание философовпрактиков вне академической среды. В книге рассматриваются главные аспекты «серьезного» отношения к философии, на основе которых для философской практики могут открыться новые перспективы развития.

Ключевые понятия: философия, философское консультирование, философская практика, мелиоризм, интеллектуальные добродетели.

\footnotetext{
Статья подготовлена в рамках задания № 35.5758.2017/БЧ «Философская практика как новая парадигма современных социогуманитарных исследований» Министерства образования и науки Российской Федерации на выполнение государственных работ в сфере научной деятельности и проекта РФФИ № 17-33-00021 «Теория и практика философского консультирования: компаративистский подход».
}

Автор книги - израильский философ Лидия Амир - хорошо известна в области философской практики. На протяжении всей своей академической карьеры она пропагандировала философскую практику как внутри академической среды, так и за ее пределами, используя свой опыт в обеих областях. Ее работы по этике, юмору и философской практике переведены на многие языки мира. Все ее книги и статьи представляют большой интерес, поскольку автору удается сочетать широкую научную эрудицию с элегантным стилем изложения. Здесь есть юмор, но, как известно, юмор для профессионала - дело серьезное. Относимся ли мы серьезно к философии? На первый взгляд - странный вопрос. Понятно, что только серьезное отношение может уберечь грандиозный философский проект от дискредитации. Но если в этом деле мы утратим чувство меры, то философия будет казаться обычному человеку затеей скучной и далекой от его насущных жизненных проблем. Автор рецензируемой книги предлагает нетривиальное решение этой дилеммы.

Традиционный взгляд на философа, витающего в облаках, сделал философию сначала смехотворной в глазах общества, а затем смехотворной для тех философов, которые отдают предпочтение практике в сравнении с теорией. Автор утверждает, что для философской практики важно разобраться не только с теоретическими вопросами относительно самой природы философии, но также определиться с целями и средствами практической деятельности, а также с характером отношений с академической традицией.

Автор поднимает эти вопросы с целью наметить рамки, в которых могут реализовывать себя все направления философской практики, не теряя при этом своих существенных особенностей. Амир также отмечает немалую роль академической философии, поскольку рассматривает философскую практику как непрерывный процесс, который начинается с успешного освоения философских теорий, что требует эффективных методов обучения, и заканчивается дальнейшей специализацией в соответствии с потребностями и способностями философствующих субъектов. Автор проводит различие между перфекционизмом - радикальной формой «философии для немногих» и мелиоризмомдемократизированной формой «философии для всех», которая, по словам Амир, может быть реализована как в академической среде, так и за ее пределами (р. 3). 
Что такое мелиоризм? В чем смысл этого понятия? Как эта концепция может помочь в решении проблем, изложенных выше? «Под мелиоризмом я подразумеваю те философские концепции, которые менее амбициозны, в большей степени соответствуют здравому смыслу, психологическим потребностям и социальным целям обычных людей, скептически относятся к перфекционистским устремлениям», - отмечает автор в своей статье «Принимая философию всерьез: перфекционизм versus мелиоризм» ${ }^{1}$. Например, «Никомахову этику» Аристотеля можно отнести к мелиоризму, исключая ее десятую главу; другими философами из этой традиции, можно считать, по словам автора, Юма, Локка, Рассела, Поппера. Инструменты для активизации человеческой свободы, в концепциях этих философов, - это не роскошь, украшающая этический проект самосовершенствования. Это необходимые средства для выживания демократии, так как они включают в себя моральные и интеллектуальные добродетели, без которых индивидуальная автономия не имеет смысла, а свобода без способности ее осознавать и реализовывать на практике - просто абстрактное понятие. Чтобы быть плодотворным, философское воспитание требует индивидуального подхода. Философская практика может играть важную роль в жизни современного общества, поскольку услуги, которые она предлагает, являются ценными и необходимыми для всех. Никакая другая дисциплина не может удовлетворить эти потребности, следовательно, философы несут за это моральную ответственность перед обществом.

В своей книге Лидия Амир обращается к незаслуженно забытой теме философского образования как наставничества посредством тонкого анализа отношений между наставником и его учеником. Она раскрывает проблемы, присущие философской практике прошлого, начиная с александрийских времен, эпохи Просвещения, XIX в., указывающие на необходимость пересмотра, переосмысления многих инструментов, средств и методов, используемых в современной философской практике. С этой целью автор заостряет внимание на проблеме диалога, самопознания и самопреобразования, ставит под сомнение целесообразность изо-

\footnotetext{
${ }^{1}$ Amir L. Taking Philosophy Seriously: Perfectionism versus Meliorism, Philosophical Practice. From Theory to Practice, Sevilla : Grupo de Investigación de la Universidad de Sevilla "Filosofía Aplicada" (HUM 018), 2006. P. 13.
}

лированного существования течений философской практики, а также сущностные различия между философией и психологией. Автор предлагает оригинальное решение обозначенных проблем, указывает на уникальные возможности философской практики, способствующие разрешению кризиса современной философии.

В первой главе рецензируемой книги представлены основные темы, которые получают подробное освещение в ее дальнейших разделах. В этой главе определяются философские цели и средства, которые способны преодолеть многочисленные «разрывы» между теорией и практикой в философии, а также между различными направлениями философской практики. Во-первых, автор заостряет внимание на значении абстрактного мышления в философской практике: «схематизация», которую оно предполагает, является ценным инструментом при условии, что она используется лишь как временное средство. Во-вторых, автор подчеркивает важность эпистемологии и разрабатывает эпистемологию интеллектуальных добродетелей как теоретический материал для философской практики. В-третьих, в силу тесной связи моральных и интеллектуальных добродетелей автор отстаивает тезис о том, что философская практика играет важную моральную роль в демократичных и либеральных обществах.

Автор приходит к выводу, что мелиоризм верен как целям (истина, освобождение, мудрость), так и методам (адекватная рефлексия, с использованием абстрактного мышления, логики и эпистемологии) философии, и в то же время такая философия может быть доступной для всех. Три инструмента мелиористской философской практики, предложенные в первой главе (приспособление абстрактного мышления к практике, воспитание интеллектуальных добродетелей и совершенствование чувств посредством моральных добродетелей), по мнению автора, усиливают автономию, свободолюбие. Укрепление личностной автономии помогает смягчить напряженные отношения между свободой и равенством, противоречивое истолкование которых порождает конфликты в любом демократичном и либеральном обществе. Эту достойную цель, считает автор, можно рассматривать в качестве главной для «демократизированной» философской практики (р. 31).

После вступительной первой главы книги следуют шесть ее основных частей. Каждая часть посвящена тому или иному 
аспекту «серьезного» отношения к философии; на этом теоретическом материале могут базироваться новые направления философской практики.

Автор начинает с рассмотрения недостаточно исследованного аспекта философского образования - отношений между наставником и учеником. Часть I «Философы-наставники и их ученики» посвящена древним философским образовательным практикам. Если для академической философии это не столь актуально, то для философской практики - это предмет повышенного интереса. Посредством исторического анализа, который проливает свет на современные проблемы, автор обосновывает необходимость учителя-наставника (Глава 2) и важность самообразования (Глава 3). Поскольку можно усмотреть противоречие между этими двумя требованиями, Лидия Амир анализирует различные методы, которые философы использовали для предотвращения или ослабления этого противоречия. Например, обучение философии как дарение, философское образование с минимальным вмешательством учителя или нетрадиционные методы обучения для поиска учеником собственного личностного пути, предполагающие весьма жесткие философские практики, граничащие с жестоким обращением с учеником и его моральным унижением. Автор критически анализирует эти методы и приходит к выводу, что вся их «хитрость» заключается в том, чтобы приобщить ученика к философскому образу жизни без каких-либо назиданий и наставлений, так как все это считалось признаком нарушения полной автономии ученика. Отказ от того, чтобы манипулировать поведением ученика, чтобы он руководствовался только собственным умом, а не «мудрыми наставлениями» учителя, и является самым верным способом сохранения автономии: ведь «знания нельзя просто передать или "вложить" в ученика, даже в виде дара» (р. 105-106).

Во второй части «Философы-практики прошлого» рассматриваются главные ориентиры философии на заре ее возникновения, некоторые из которых могут быть весьма полезными, а некоторые очень опасными для нынешних подражателей. Здесь речь идет главным образом об эллинистической философии - стоицизм, эпикурейство и пирронизм, а также кинизм (Глава 4), о «сократе» английского просвещения графе Шефтсбери (Глава 5) и о датском философе XIX века, предшественнике экзистенциа- лизма, С. Кьеркегоре. В Главе 6 Лидия Амир обосновывает мысль о том, что экзистенциальные проблемы, поднятые Кьеркегором, позволяют prima facie рассматривать его как предшественника современной философской практики. В частности, она выделяет концепт «субъективной рефлексии» Кьеркегора как особо значимый для понимания взаимного отношения между конкретным и абстрактным, и делает вывод о том, что данный концепт можно рассматривать в качестве парадигмы всей философской практики (р. 180-181).

Часть III «Незаслуженно забытые темы» посвящена четырем нетривиальным практическим вопросам, которые, несмотря на чрезвычайную важность, обычно игнорируются как в академической философии, так и в философской практике. В Главе 7 рассматриваются причины современного «холодного» отношения к основным положениям этики Бенедикта Спинозы, хотя именно у него представлено деление добродетелей на эпистемологические и моральные, что может открыть новые возможности для развития философской практики. Глава 8 посвящена анализу феноменов человеческого существования, среди которых особое значение автор отводит юмору, что недостаточно учитывается в философской практике, хотя юмор, в известном смысле, можно считать инструментом выживания человека, смягчающим состояние безысходности. Глава 9 затрагивает еще одну незаслуженно забытую тему западной философии - воспитание воли, необходимость волевых усилий для самосовершенствования человека, что дает возможность философии позиционировать себя в качестве духовной альтернативы религии. В этой главе автор анализирует программу философской практики, предложенную известным религиозным философом Р. Невиллом для воспитания воли с целью достижения самосознания через самооценку, действие, осознанность и ответственность. Критически анализируя эту программу, автор предлагает философский инструмент для достижения человеком автономности в условиях потери жизненных идеалов, как альтернативу разнообразным «восточным практикам» или психоанализу. «Когда консультант открывает клиенту возможности для философского образа жизни, а не просто дает историческую справку по этому вопросу, синтез западных и восточных знаний о роли волевых усилий в жизни человека может оказаться полезным. Или же, в 
качестве альтернативы, можно сослаться на свой образ жизни, помня при этом, что юмор является действенным философским инструментом освобождения», - пишет Лидия Амир (р. 247). По мнению автора, этот трудный путь может быть смягчен умелым использованием юмора, и, хотя воспитание воли может оказаться делом всей жизни, вознаграждение будет пропорционально затраченным усилиям.

Особое внимание следует обратить на Главу 10, рецензируемой книги, в которой в повестку дня философов-практиков включается тема сексуальности. Поскольку любые публичные разговоры о сексуальности так или иначе осуждаются общественной моралью, относятся к области секретного и даже запретного, философ должен взять на себя личную ответственность за разработку сексуальной этики. Исследование именно этического плана сексуальности как одного из условий радостной и хорошей жизни - это, по мысли автора, дело философов и философов-практиков. Сексуальность дает уникальную возможность насладиться нашей биологической природой, однако - это исключительно человеческий опыт. «Реабилитация» этических сторон сексуальности, гармонизация эроса, всего того, что может служить источником жизненной активности человека, представляется весьма трудным проектом. Тем не менее, автор считает, что за этот проект стоит браться, опятьтаки, не забывая о юморе, который может также служить подспорьем и в этом вопросе. Философия может внести свой вклад в определение и исследование значения сексуальности в жизни человека, открыть новые возможности, помогающие использовать энергию эротизма для улучшения и даже совершенствования его душевного состояния, для освобождения от иллюзий и предрассудков в этой области, не ставя под угрозу моральную целостность его бытия. Автор отмечает, что для философов-практиков, работающих с душевными состояниями клиента, непростительно быть неподготовленными или излишне стеснительными в этой области, нужно оставаться до конца верным своей философской миссии. Эта миссия тем более важна в наше время, когда различные нарративы эмансипации переплетаются в запутанный клубок вместе с разнообразными социальными и политическими программами. Все это оттесняет на задний план этический долг человека перед самим собой, но в либеральных обществах в условиях свободы и равенства на челове- ка налагается гораздо большая личностная ответственность, чем было ранее, отмечает Лидия Амир (р. 272).

Часть IV рецензируемой книги посвящена пересмотру средств философской практики. Со времен Сократа самопознание и диалог являлись главным предметом интереса философов-практиков. Три главы, составляющие эту часть книги, критически оценивают возможности самопознания, учитывая преобладание фактора бессознательного как в самой философии, так и в психологии, а также возможности диалога, как внутриличностного, так и межличностного. Можно утверждать, что душевные страдания клиента могут стать стимулом для самотрансформации. Более того, можно даже убедить клиента в том, что рациональные усилия устранят болезненные и неприятные эмоции, при этом рациональность не обязательно должна стать для него единственной программой самореализации, а лишь использоваться в качестве инструмента для улучшения его состояния. Эта стратегия, однако, базируется на другой форме рациональности - способности соотносить цели и средства. Автор не разделяет мнение, что философы-консультанты должны гарантировать фундаментальные изменения душевного состояния клиента. Никто не может предугадать заранее, какие конкретные изменения произойдут, и произойдут ли они вообще. Мы знаем одно: только тогда, когда человек реально станет готов к переменам, это все заработает. Клиенты, не только благодаря полученным знаниям, но и во многом благодаря личности консультанта, могут обнаружить в себе жажду самосовершенствования, которая может привести их к философии, открывая перед ними новые горизонты (р. 319-320). Так обретает силу практика внутреннего диалога. «С этой точки зрения я делаю две вещи, - пишет Лидия Амир, я постепенно обращаю вашу речь ко мне к вам самим; я призываю вас слушать вашу речь посредством, хотя и более удаленного, но более информированного внутреннего слушателя. То есть, во-первых, я призываю вас прислушиваться к своему внутреннему голосу, чтобы вы лучше поняли свою речь, и, во-вторых, прислушиваясь к внутреннему голосу, открыть для себя нечто большее, чем то, что было услышано в первый раз. Таким образом, я даю вам гарантирую, что даже в мое отсутствие ваш внутренний диалог не прекратится, более того, он будут все более богат смыслами, а его границы 
будут все более широкими. Именно внутренний диалог открывает способность к философской рефлексии: если внутренний слушатель останется не более чем дубликатом меня самого, просто моим внутренним «эхом», никакого самообразования, саморазвития, критической, а значит, и творческой рефлексии произойти не может» (р. 345). Таким образом, включение в себя безличной инаковости, которая есть не что иное, как обобщение и абстракция нашей человечности, является в философской практике самым существенным.

В Части V, состоящей из двух глав, автор дает критический анализ инструментам, используемым в философской практике. В Главе 14 представлена авторская методика философской практики, которая позволяет сохранять «серьезное» отношение к философии. Эта методика предлагает философские цели и философские средства для их реализации, опирается именно на философский инструментарий, а не на другие способы консультирования, для реализации которых философы могут быть просто не готовы. Методологический принцип автора прост - «меньше консультирования, больше философии». Лидия Амир объясняет суть своего принципа посредством достижения следующих целей: 1) совершенствовать абстрактное мышление, переходя от конкретного к абстрактному и наоборот; 2) пробуждать интеллектуальные добродетели с конечной целью развития интеллектуальной смелости и самостоятельности; 3) укреплять внутренне единство личности, ибо беспристрастных мыслей для мудрости недостаточно, необходимы и глубокие чувства (р. 359). Реализация всех этих целей является необходимым условием «демократически ориентированной» философской практики.

В Главе 15 автором рассматривается «трудная проблема» самотрансформации с помощью философских инструментов, что необходимо для достижения счастливой, осознанной жизни. С этой целью автор дает критический анализ основным философским измерениям «благой жизни»: соотношению трагического и комического, условиям самопознания, способности принимать жизнь во всей ее противоречивости, способности понимать. Кроме того, автор подробно рассматривает связь между разумом и эмоциями, между радостью и страданием, как условие для того, чтобы наполнить жизнь смыслом и развить сострадание. Автор предполагает возможность жить с неразрешимым конфликтом, однако в конечном итоге, любой конфликт, характеризующий основное состояние человека, может быть разрешен. Инструментом для этого, по мысли автора, является юмор. Посредством процесса, включающего в себя систематическую практику юмора, мы дисциплинируем свой вкус, находим удовольствие в противоречиях, в которых ранее мы не видели ничего смешного, постепенно поднимаемся по лестнице совершенства, которая приводит нас к состоянию, сравнимому с высшими философскими или религиозными озарениями. Эта постепенная трансформация основана на изменении видения в соответствии со способностью, по словам автора, «превращать страдание в радость посредством алхимии юмора» (р. 387-388).

В Части VI («Проблемы и достижения») рассматриваются препятствия, с которыми сталкивается философская практика, которые сводятся в глазах академической философии к «сомнительным допущениям», лежащим в ее основе (Глава 16). Однако наряду с этим автор отмечает те уникальные преимущества, которые философская практика может дать академической философии (Глава 17). Эта последняя глава вовлекает читателя в оживленную дискуссию, которая помогает осознать и преодолеть разрыв между теорией и практикой в философии. Поскольку большинство студентов, изучающих философию, не будут заниматься этим профессионально, преподаватели философии могут использовать опыт философовпрактиков в своей работе, выстраивая взаимодействие с самой разной аудиторией. В связи с этим автор предлагает разрабатывать некий критерий релевантности для оценки учебного плана и способа преподавания философских теорий. Эти разработки могли бы способствовать распространению философии, так как любая аудитория смогла бы получить от этих занятий что-то полезное, что обеспечило бы достойное место философии, как в академической среде, так и за ее пределами.

Заключительный раздел книги также весьма интересен и содержателен. Он представлен в форме увлекательного интервью с автором, в котором даны краткие ответы на все ключевые вопросы, связанные с философской практикой.

Книгу Лидии Амир «Принимая философию всерьез» можно по праву назвать «энциклопедией» философской практики, которая обобщает богатый опыт прошлого и открывает широкие перспективы для бу- 
дущего в этом философском направлении. В этой книге сочетаются высокие академические стандарты рассмотрения проблем и доступный стиль изложения, поэтому она будет интересна как представителям академической среды, так и философам-практикам, преподавателям, психологам, а также широкой публике.
For citing: Borisov S.V.

Encyclopedia of philosophical practice

(book review: Amir L. Taking Philosophy Seriously, Cambridge Scholars Publishing, 2018, 504 pp.) // Socium i vlast'. 2019. № 2 (76). P. 132-137.

UDC $1(091)+101.1+101.9$

\section{ENCYCLOPEDIA OF PHILOSOPHICAL PRACTICE (BOOK REVIEW: AMIR L. TAKING PHILOSOPHY SERIOUSLY, CAMBRIDGE SCHOLARS PUBLISHING, 2018, 504 pp.)}

\section{Sergey V. Borisov,}

South Ural State Humanitarian

Pedagogical University,

South Ural State University

(National Research University),

Doctor of Philosophy, Professor.

Russian Federation,

454080, Chelyabinsk, prospect Lenina, 69.

E-mail: borisovsv69@mail.ru

\section{Absract}

The article is a review of Lydia Amir's book "Taking Philosophy Seriously" (Cambridge Scholars Publishing, 2018). The book synthesizes academic and practical philosophy, initiates a meta-philosophical dialogue. The author adheres to the melioristic view of philosophy that rethinks the approach to philosophy, reinvigorates its academic teaching and secures the respectability of its practitioners outside the academic environment. The book considers the main issues of a "serious" attitude to philosophy on the basis of which there can be opened new prospects for philosophical practice.

Key concepts:

philosophy,

philosophical counseling,

philosophical practice,

meliorism,

intellectual virtues. 